\begin{tabular}{|c|}
\hline 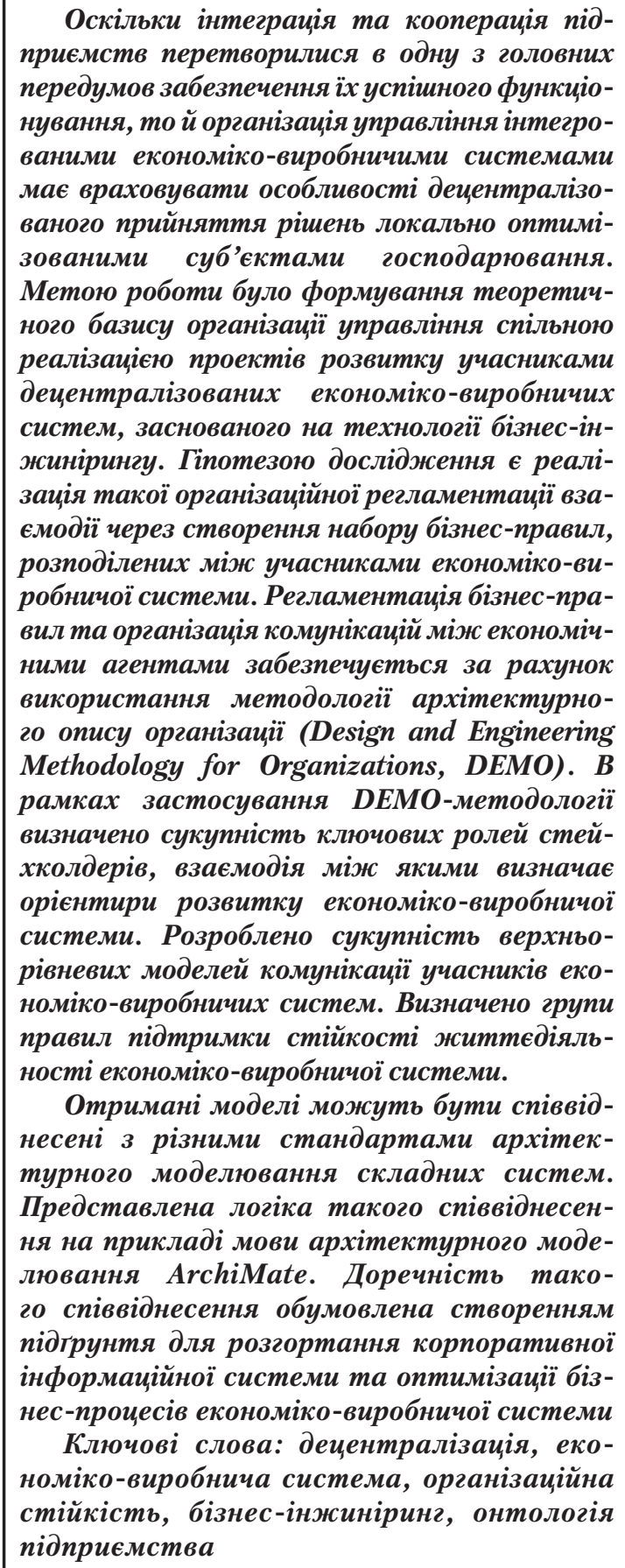 \\
\hline
\end{tabular}

Received date 25.05.2019

Accepted date 02.08.2019

Published date 30.08.2019
UDC 334.78:338.48

DOI: $10.15587 / 1729-4061.2019 .175765$

\section{ORGANIZED MANAGEMENT OF DECENTRALIZED ECONOMIC PRODUCTION SYSTEMS WITH JOINT IMPLEMENTATION OF DEVELOPMENT PROJECTS}

M. Korneyev

Doctor of Economic Sciences, Associate Professor Department of International Economic Relations,

Regional Studies and Tourism

University of Customs and Finance

Volodymyra Vernadskoho str., 2/4, Dnipro, Ukraine, 49000

E-mail: km_13_15@ukr.net

A. P y l y pe n k o

Doctor of Economic Sciences,

Professor, Head of Department

Department of Accounting and Business Consulting Simon Kuznets Kharkiv National University of Economics Nauky ave., 9-A, Kharkiv, Ukraine, 61166

E-mail: aapil@ukr.net

O. P o p o v

Doctor of Economic Sciences,

Professor, Head of Department

Department of Physical Culture Management Kharkiv State Academy of Physical Culture Klochkivska str., 99, Kharkiv, Ukraine, 61058

E-mail: aepopov@ukr.net N. S h m a t k o

$\mathrm{PhD}$, Associate Professor

Department of Management of Innovative Entrepreneurship and International Economic Relations National Technical University "Kharkiv Polytechnic Institute" Kyrpychova str., 2, Kharkiv, Ukraine, 61002 E-mail: shmatko.khpi@gmail.com

\footnotetext{
Copyright (C) 2019, M. Korneyev, A. Pylypenko, O. Popov, N. Shmatko. This is an open access article under the CC BY license (http://creativecommons.org/licenses/by/4.0)
}

around itself. Prolonged cooperation of the participants in these networks leads to the establishment of institutional norms of interaction, the creation of a permanent list of business rules, and devising a certain organizational design. However, there may be a fairly wide variety of organizational and legal forms of interaction of market participants, which are proposed to be identified as economic production systems (EPSs). Such EPSs can be corporate enterprises within networks of interaction, industrial clusters and all types 
of network structures, decentralized holdings and virtual enterprises. It is even possible that EPSs may be based on Uber's principles (USA) when independent market participants interact based on certain rules of the management company. The emergence of an Uber-type EPS is due to the fact that it is not always cheaper or more profitable to organize communications within a company than to establish external connections.

Organized management of such EPSs should be based on a completely different ground, which will take into account the institutionalization of relations between EPS participants. The implementation of managerial influences, in turn, can confront a number of problems, the main ones being conscious violation of established agreements, refusal of some EPS participants to perform their assigned business roles, and the inability to fulfil the parameters of a consolidated business plan. Some of these problems are related to setting the optimal parameters for organizing EPS activities, because it is at the stage of organizing the interaction of EPS participants that most of the possible problems can be anticipated and instruments of coercion to perform business roles can be set. Additional problems not specific to the current activities appear at the stage of developing an EPS. Development leads to the emergence of new qualities in the system, which in turn requires a change in the current approach to the EPS management. With this approach, the problem of developing a theoretical and methodological basis for organizing the management of the EPS participants' engagement is actualized. The complexity of solving this problem lies in a relatively high level of decentralization of EPSs due to a large number of decision-makers. It is not so much about specific decision-makers as it is about the presence of separate strategic business units in the EPS structure. Depending on the type of EPSs, such business units can be either individual enterprises or organizationally separated units, branches and subsidiaries. The independence of such strategic business units shifts the focus of research to decentralized economic production systems (DEPSs).

\section{Literature review and problem statement}

Studies [1-27] are devoted to researching various aspects of establishing and supporting economic production systems. Typically, the level of decentralization of economic production systems is not considered in these studies as the main criterion of organization and optimization of the processes of their management. When organizing the management of DEPSs, the proposals [1,2] for identifying them as "systems of systems" should be taken into account. According to [1], such "systems of systems" are identified as having arisen as a result of integration into a single network of a finite number of independent, capable and cooperating systems. It is believed that this study should be expanded by introducing mandatory criteria for attracting business entities into a single network, which should be a commonality of goals and an obligatory manifestation of emergent properties. A suggestion is that the appearance of emergent properties should act as a criterion for organizing management of the DEPS development. Contrary to this, the researchers in [3,4] mostly rely on the effect of synergy. It is the focus on emergence that will contribute to the appearance of the DEPS development projects.

The authors of [2], in their turn, use the concept of "systems of systems" to describe the virtualized interac- tion and to ensure the compatibility of enterprises within an economic production system through the creation of a holistic service-oriented architecture. However, although the construction of such a design contributes to the effectiveness of interaction, it may to some extent inhibit the development process precisely because of the desire to maintain the immutability of the service system. Accordingly, the organization of management of the DEPS in such a case should determine the directions of transforming the architecture of the economic production system and coordinate such directions with all participants in the framework of a certain communication process, which also needs a proper organization. The requirement for the organization of proper communications is also contained in [5], which describes the peculiarities of organizing through-line business processes of individual enterprises. Such features are highlighted in terms of the concept of "interoperability", that is, the ability to interact. The management contours, according to the authors of [5], are built around performance indicators and goals distributed over the perspectives of a strategic map of a balanced scorecard. Accordingly, the organization of management of a DEPS should determine the desirable values of performance indicators precisely within the framework of a certain negotiation process, which is not mentioned in [5].

In the context of the commonality of development goals, it is reasonable to state [6] that integrated entities of corporate enterprises as one of the forms of DEPSs are locally optimized. In [6], it is rightly emphasized that for locally organized economic systems there is a clear awareness of the characteristics and parameters of operation of component systems (economic entities within a DEPS) with a low degree of understanding the characteristics of the DEPS as a whole. The provisions of this study should be extended to EPSs with a higher level of decentralization in which it is even impossible to single out an entity. Such EPSs are defined in [7] as enterprise cluster systems that have not been fully created by anyone yet. The organization of management of such DEPSs is difficult because the participants may change their own goals during the system's operation and there is no single entity responsible for the design of the DEPS. From this point of view, it should be agreed [8] that centralized ownership of a system involves the presence of stakeholders who have the power and ability to control all elements of the system.

Identification of a DEPS as a system of systems does not imply the selection of one specific person who will make key decisions on the development of the DEPS. Thus, it is the independence of key stakeholders that requires founding the DEPS development management on some organizational support that will be based on regulating the negotiation process between such stakeholders. Such a negotiation process should take place around a specific global description of the DEPS. Such a description in $[8,9]$ is defined as "business architecture", containing the identification of critical processes of the DEPS, its functions, parameters of interaction between its elements, and concerted goals.

In the context of such understanding of the business architecture, a certain layer of research is actualized as uniting the strategy and structure of a company. In the context of organizing DEPS operation management, two opposite approaches should be considered. The first approach, outlined in [10], supports the thesis statement that the organizational structure and other parameters of organizing EPS activities are determined by the chosen strategy. There is a contrary 
view [11], where it is argued that the structure provides uniqueness of the chosen business model (that is, the structure determines the strategy, not the other way around). According to the authors, in forming organizational support for the development of a DEPS, it will be more effective to focus on the cyclical alternation of these statements when a change of the structure or strategy initiates a new negotiation process between the participants of the decentralized economic production system. The results of such a negotiation process, established in the form of specific regulations and business rules, will form the basis of organizational support for the development of the DEPS. The difficulty of creating such organizational support will be not so much in determining the priority of the structure or strategy but in the transformation of the existing developments $[10,11]$ in terms of concerted development of the strategy and formation of the structure of the DEPS.

There are a number of problems in the formation of organizational support for the DEPS development management, which are individually characterized in the economic literature but which require concerted consideration. The first problem is that when talking about systems of systems, the possibility of having different degrees of decentralization should be taken into account. A single large enterprise can also be considered as a system of systems, precisely because of the presence of several strategic business units in its structure. An example here is the suggestions $[12,13]$ that highlight the issues of organizing the management of such strategic business units within large corporate structures. Thus, in [12], there is a study of the correspondence of the adopted corporate control mechanism and the effectiveness of strategies of individual business units. This study proves that strategic management is more important than the characteristics of financial control over a corporation. However, the communication aspect of coordinating the parameters of strategies of individual business units of the corporation, which is necessary for certain types of corporate control, is not considered in [12]. Interesting from the point of view of distributed decision-making is study [13], which highlights a relationship between corporate control of the holding structure and the speed of decision-making at the level of strategic business units. The authors of [13] identify the types of corporate control organization that increase the speed of decision-making but do not sufficiently reflect the organizational regulation of the interaction between individual strategic business units. Accordingly, it is important to take into account the studies [12,13] regarding the formation of protocols of interaction between participants of holding and corporate structures focused on supporting the efficiency of economic activities and making appropriate strategic decisions

Another problem is the so-called heterogeneity of the DEPS. The theoretical analysis of this concept, carried out in [14-16], has revealed various forms of manifestation of heterogeneity and its influence on the parameters of organization of management of the economic production system. Thus, in [14], the features of decentralized decision-making at the macroeconomic level with regard to information imbalance are considered. It is the asymmetry in access to information that complicates the development of the DEPS strategy and needs to be taken into account in the organizational structure of the DEPS. For this purpose, the findings of [14] must be adapted to the requirements of a lower level of the hierarchy of an economic system. In [15], the signifi- cance of the influence of the heterogeneity of an enterprise and the differences in the degree of technical cooperation of the DEPS participants on the spread of technological innovations are investigated. The presence of such innovations is a prerequisite for the development of any economic system. Accordingly, the organization of the DEPS development management should take into account the level of such heterogeneity, although the authors of [15] do not pay attention to management aspects and merely cover groups of indicators in assessing the level of heterogeneity. An important managerial decision in the context of the concept of the DEPS heterogeneity is the wish to overcome it by eliminating inefficient and unqualified enterprises from the DEPS. Similar suggestions are presented in [16]. At the same time, they are focused only on the virtual interaction of enterprises and require refinement of the economic production systems present in the physical world with a well-designed organizational structure.

An exemplary case study is [17], in which the theory of the development of inhomogeneous economic systems is developed. However, it is limited to a rather broad description of the types of heterogeneities and the introduction of a number of classification features. These are features such as mode of interaction, degree of maturity, forms of manifestation, and nature of development. Although a positive component of [17] is the identification of the heterogeneity of time, space, interaction, methods of coordination, resources, institutions, and technologies, these types of heterogeneity are proposed to be taken into account in the process of organizing the management of mutual implementation of the projects of the DEPS development during the regulation of communication acts of the DEPS participants. Based on previous research [14-17], when forming the organizational support for the management of the DEPS, it is necessary to take into account the situation of an asymmetry of the development of individual systems within the DEPS. This requirement closely intersects with the concept of economic power, which is described in some detail, for example, in $[18,19]$. Thus, the detailed list of tools and sources of manifestation of economic power, defined in [18], was used in [19] to form a network of creation and distribution of added value between aircraft-building enterprises. It should be noted that the developments [19] are predominantly focused on the market power of an enterprise, whereas in the context of the DEPS it is necessary to examine the power in the context of decentralized decision-making. Such a change in the orientation of the study places additional requirements on the consideration of organizational support for the management of the DEPS development and on the establishment of a stable communication process for the DEPS participants.

Another aspect of the organization of the DEPS development is related to the scope of activities of business associations. The increase in the activities has led to the emergence of elaborations on the issues of creating and organizing the management of large-scale economic production systems. In particular, requirements for institutional structuring of large-scale EPSs are explored in [20], and features of information consolidation regarding the management needs of such EPSs are highlighted in [21]. In addition, requirements for achieving organizational and communication sustainability of large-scale systems are established in [22]. Accordingly, these achievements need expanding to take into account the possible decentralization of the organizational 
structure of large-scale EPSs. Meanwhile, the scale and heterogeneity of the DEPS require the addition of one more property to the existing studies related to the asymmetry of changes and the asymmetry of the DEPS development. As a rule, researchers emphasize only the objective availability of information asymmetry that influences the management of decision-making as to the development of an entity. Such an emphasis on the existence of information asymmetry is predominantly inherent in the institutional economic theory. In particular, in [23], the manifestation of asymmetric information is considered as a prerequisite for the emergence of opportunistic behaviour. The authors of this study shed light on the most common techniques for manipulating information to influence the behaviour of interaction agents. The organization of the DEPS development management should take into account such techniques, although the management processes are not considered directly in [23]. There is also a certain layer of research in which asymmetry is understood to mean different levels of development of the components of an economic system. For example, in [24], asymmetry is researched within a country-by-country representation as a "system of systems" for the choice of infrastructure solutions. It is appropriate to integrate such multivariate decisions into the contours of the organization of the DEPS management. The taxonomy of the Enterprise Resource Planning (ERP) of manufacturing enterprises is oriented to overcome the asymmetry. On the basis of this taxonomy, it is possible to identify the main components of consolidated management of the economic production system, but it needs to be expanded to take into account the availability of specific systems of goals of the ERP system participants.

In this context, the suggestion of [26] to consider the economic production "system of systems" primarily as a social phenomenon should be supported. In such a system, people interact to implement common agreements. An instrument of implementing such arrangements can be the discipline of ontological engineering described in [27], which models the construction of an economic production system through a set of organizational roles. Accordingly, it can be predicted that determining the list of such roles will establish the basis of organizational support for managing the development of the DEPS.

The application of the methodology of ontological engineering in relation to a large-scale economic production system has already been considered in [22]. Due to its focus solely on rigid integrated entities, this development needs to be expanded to take into account the specifics of decentralized interaction between business entities. The main difficulty here is to define the role system of the participants in their decentralized interaction. This is possible only if there is a clear identification of some common interest of the interaction participants, which is quite difficult to do in the context of a decentralized, large-scale, locally optimized, heterogeneous economic production system with asymmetric information distribution between its participants. It is this complexity that determines the problems of the study.

\section{The aim and objectives of the study}

The aim of the study is to formulate the theoretical basis for the organized management of the development of a decen- tralized economic production system through the regulation of the interaction of its key stakeholders.

To achieve this aim, the following objectives were set:

- to determine the features of applying business engineering technology to organize the management of interaction of participants of decentralized economic production systems in development projects;

- to establish a set of key roles of stakeholders and to define their place in the system of decentralized development of managerial decision-making;

- to develop a set of communication models of participants of economic production systems, aimed at supporting the rules of development and implementation of consolidated managerial decisions.

\section{Materials and methods for researching the process \\ of organizing the interaction of economic systems' participants in implementing development projects}

Taking into account the complexity of the relations between the participants of decentralized economic production systems for the management of joint development projects, it is proposed to use the Design and Engineering Methodology for Organizations (DEMO) developed in [28]. Within the framework of the DEMO methodology [28], the economic production system is represented as a network of distribution of interaction and responsibility based on the common ontology (common subject domain understanding) adopted by the EPS participants. Such a network, according to [29], is a map of the most important agreements on the types of the DEPS activities. The implementation of such agreements, in turn, is described as a set of communication and product acts [28]. In this aspect, the DEMO methodology distinguishes the communication and production activities of the socioeconomic system in the management processes. Moreover, based on the statement in [30], it is proposed to use the description of the interaction of elements of a corporate architecture as a tool for organizing the DEPS management. A similar approach was used in the monograph [31] to regulate the interaction of the DEPS participants. This logic broadly complies with the approach declared in ISO 24748-2 [32] to create a communication system for the implementation of a specific project. The disclosure of this logic in relation to the DEPS is shown in Fig. 1. The main advantage of using the series of ISO 24748 standards for organizing the work of the DEPS is the separation of the target system and the security system. The target system will be the value offered by the DEPS. The security system is formed from organizations within the DEPS. Accordingly, the management organization will determine the requirements and benchmarks for maintaining the selected trajectory of the target system over its life cycle. In the context of organizing the management of the DEPS development, it is proposed to extend the DEMO methodology characterized in [33] by the concept of organizational capabilities, which is understood as the ability to perform certain activities within given resource constraints. As can be seen from Fig. 1, the hypothesis of the study is the use of DEMO communication acts to coordinate the parameters of development projects of individual participants of the DEPS within the framework of compliance with existing arrangements for the implementation of DEMO production acts. 


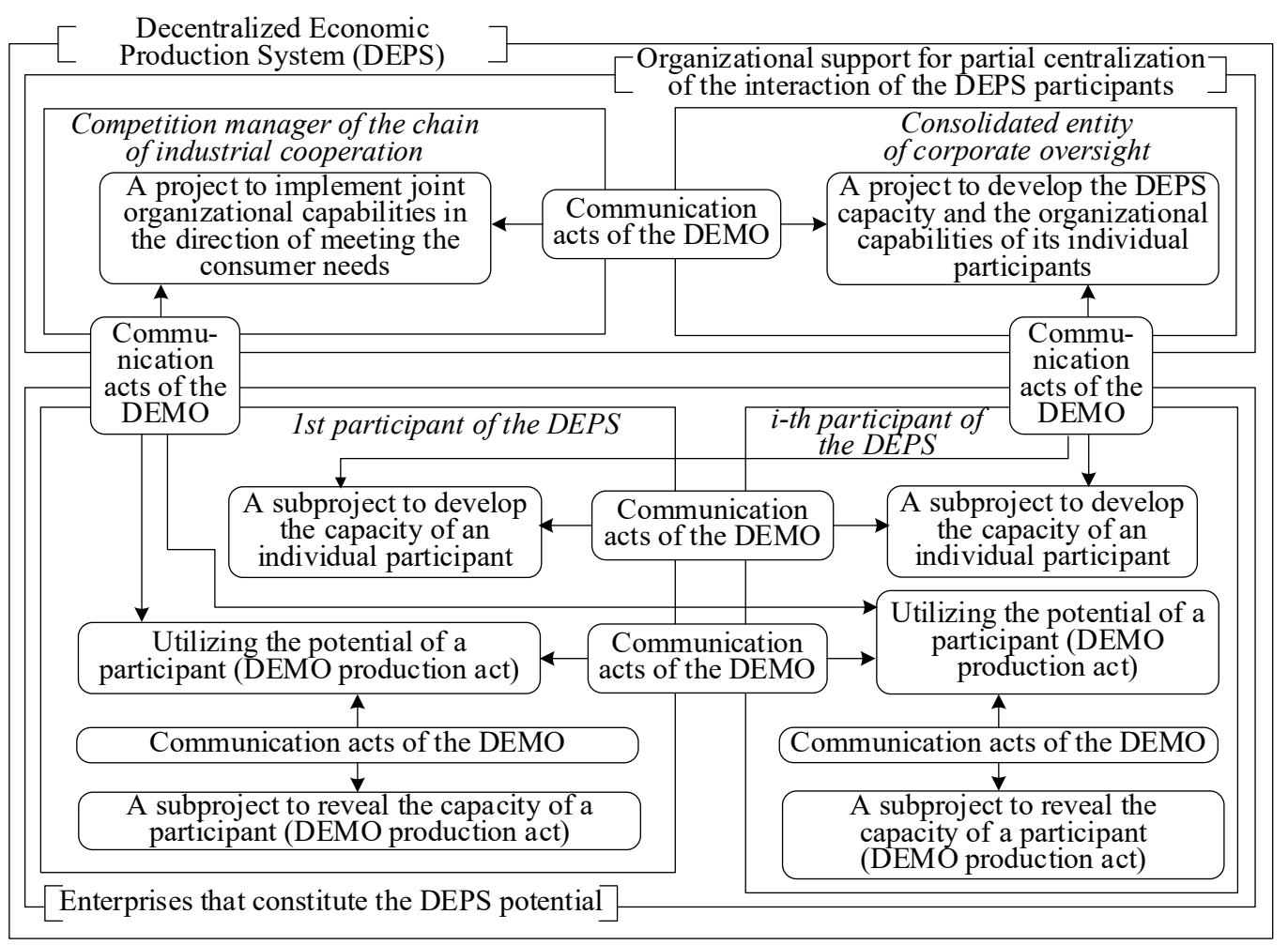

Fig. 1. Based on ISO 24748 [32], the logic of organizing the management of functioning and development of a decentralized economic production system

Orientation towards the logic of establishing the interaction of the DEPS participants, as presented in Fig. 1 makes it possible to involve the results of studies devoted to the concept of Enterprise Interoperability [34,35] in the methodological basis of the organization of the DEPS management. It is the application of this concept that helps establish an ontological basis for optimizing the interaction of the DEPS participants by any jointly defined optimization criterion. Such a criterion may be, for example, the stability criterion declared in [35]. However, this development should be expanded by adding the rest of the above-mentioned features of the vital functions of the DEPS to the criteria of optimization.

\section{The results of studying the problem of regulating the interaction of participants of decentralized economic production systems}

5. 1. Features of organization of management of joint development of participants of decentralized economic production systems

The organization of management of the DEPS in the process of functioning and during the implementation of development projects requires some organizational support. When organizing such management, it should be envisaged that there are a number of stakeholders, their roles and their views on the DEPS development benchmarks. It is necessary to distinguish between the models of processes of functioning and development of the DEPS. From the point of view of functioning processes, the developed model of management organization should help, first, coordinate the parameters of interaction of the DEPS participants. Second, such a model should allow the communication of an individual DEPS participant with the rest of the entities. In the context of devel- opment processes, the devised organizational models should help solve two main problems. First, it is the organization of interaction between the participants of the DEPS in determining the guidelines for the development of the economic system as a whole. Secondly, it is the establishment of communications regarding the perception of new development targets by an individual participant of the DEPS.

Correspondingly formed models of interaction of the DEPS participants should promote two types of decisions within the DEPS. These can be strategic resolutions. Such decisions require rational organization of the negotiation process of the DEPS participants in determining the characteristics of the strategy and organizing their interaction during the implementation of the DEPS strategy. It is also appropriate to distinguish tactical decisions that are focused on managing deviations from the chosen DEPS trajectory. Organizational support for such decisions also provides for the regulation of the negotiation process. Strategic decisions determine the business rules for the engagement of the DEPS participants and require the development of coercive mechanisms to comply with such business rules. Tactical decisions are based on modelling the operation of such mechanisms. Modelling these types of solutions in the context of the economic system decentralization goes beyond the common "principal-agent" relationships described in [36]. Accordingly, it is DEMO models, expanded by the achievements of the institutional economic theory, that will form the basis of organizational support for the management of the DEPS development. As a rule, in the literature, the implementation of the DEMO methodology is revealed by the example of an enterprise that produces one type of product. An example here is a basic study of the DEMO methodology [28] and its numerous extensions [29,30,37]. These developments [28-30,37] are built around a description of the work of a pizza business, with only three stakeholders 
and two activities identified. Similar examples are studies of car rental business processes [37] and the customer order lifecycle [38]. This approach needs to be expanded to the level of industrial cooperation of the DEPS participants. This will allow taking into account the relations of decentralization in the formed organizational support as well as predicting the asymmetry of changes in the DEPS development. A description of such industrial cooperation under the DEMO approach [28] will entail the creation of four types of system descriptions: descriptions of its design, processes, states, and actions. It should also be noted that the use of the DEMO methodology for the creation of an industrial cooperation network and the harmonization of attributes of value creation within the framework of tactical decisions are described in detail in the monograph [31]. The main idea [31] is to use the organizational capabilities of the DEPS participants to meet consumer needs. According to this idea, production and communication acts are presented in Fig. 2. In this case, an individual entity B-A01 executes the consumer order and forms the necessary chain of industrial cooperation.

participants of the DEPS to obtain the to-be model. It should also be noted that the model cited in the article can be considered as a to-be model in relation to the previous developments by the authors [22,31], where the as-is model is presented for coordination of interaction of participants of large-scale economic production systems. The proposals for the optimization of the list of agents and the composition of the transaction can be identified as an act of organizational development. An important task in developing a to-be model is to determine the composition of the main stakeholders of the DEPS. According to the DEMO approach, it is argued in [39] that the organization of the DEPS work is more focused not on the set of economic entities entering the economic system, but on the roles they perform.

Therefore, the construction of any economic system within the DEMO approach is modelled through the definition of transaction types and actor roles. As can be seen from Fig. 3, such roles are divided between productive acts (that is, aimed at implementing the mission of the DEPS activities) and coordination acts (that is, by accepting mutual commitments to implement the product acts by the participants). The model presented in Fig. 3 is generally based on the logic of interaction of business entities in the consolidated use of organizational capabilities, outlined in Fig. 1. This model is identified in the DEMO terminology as a "Global Actor Transaction Diagram”. To build it, the Modelworld modelling system [40] is used, which allows the different levels of the DEMO model description to be integrated into one unit. Substantially, the above

The flowchart of Fig. 2 can be used to make strategic decisions, too. In contrast to the developments in [22, 31], it is proposed to use the DEMO methodology not for the formation and regulation of the functioning of the industrial cooperation network but for the development of benchmarks for the management mechanism of the DEPS development. At the same time, it is proposed to consider development not as abstract qualitative, structural and quantitative changes, but as specific projects for implementing such changes. It is in this case that the organization of the management of the DEPS development is reduced to determining a system of requirements and restrictions for development projects of each of the DEPS participants, as outlined in Fig. 1.

\section{2. Creating a top-level model and identifying key} roles of the stakeholders in the system design

Organized management of the DEPS development requires determining its features precisely in the absence of centralized implementation of managerial influences. Development is generally regarded as a transition from an existing state (defined by the as-is model) to a state with new advanced qualities (defined by the to-be model). There is now some criticism of the approach to the formation of the as-is and to-be models when the emphasis is on the appropriateness of starting modelling immediately from the formation of a promising model. Taking this approach, we hypothesize that the development of the DEPS will be based on regulating DEMO communication acts of the negotiation process regarding the parameters of implementing the necessary changes by the model proposes the selection of four aggregate elements. First, the industrial cooperation chains of the DEPS participants, which ensure the creation of consumer value and the involvement in the consolidated implementation of the development projects in the DEPS. Secondly, it is the consumer enquiry identification entity that provides situational formation and reformatting of the industrial cooperation network. This is the subject of any of the participants of the DEPS that begins the process of performing the B-A01 role indicated in Fig. 3. Thirdly, the establishment of organizational support for the interaction of the participants of the DEPS is envisaged based on partial centralization of the function. It is in the framework of such provision that a consolidated vision of the DEPS marketing strategy is formed and certain business rules of joint activities are defined. Therefore, in [31], it is suggested to identify a number of key economic entities that make up the so-called "DEPS core". It is around their interaction that the value supply of the market is formed by the DEPS. The appropriateness of allocating such a nucleus is explained by the need to maintain a certain organizational flexibility of the DEPS while fulfilling the requirement of sustainability of its vital activities. It is within the framework of this proposal in Fig. 3 that the formation of an industrial cooperation network is envisaged not on the basis of vertical or horizontal integration but through the development of a system of institutional agreements and requirements for business processes. The management organization in this case implies determining a set of business rules and guide- 
lines for the management systems of individual participants of the DEPS. The fourth aggregate element is the mapping of the roles of strategic business units within the DEPS. It is envisaged that the final development projects for the development of such strategic business units will be based on their communication with each other within the framework of the benchmarks established by partial centralization.

The model outlined in Fig. 3 is the basis for a more detailed presentation of the interaction of the DEPS participants and the organization of managing the development of such interaction. This model displays a list of transactions and clearly identifies the initiators and executors of such transactions. This creates the prerequisites for the development of rules of vital activities of the DEPS, which are hypothesized to form the basis of organizational support for managing the development of the DEPS.
5. 3. Modelling of coordination acts of the DEPS participants and identification of the structure of communication interaction results

Orientation towards the model of the economic system design in Fig. 3 helps establish the one presented in Fig. 4 as a model of transactions in which the participants of the DEPS are involved. In the DEMO terminology, the flowchart of Fig. 4 is identified as an Actor Transaction Diagram. This model primarily details the interaction and determines the basis of the communication process. Each transaction is formed in terms of the chain "request - promise - performance of the actor role - confirmation of performance acceptance or refusal of result". In Fig. 4, such interaction within the frames of Fig. 4 is shown in the section of the set of product acts outlined in Fig. 3 (defined by the set $\{T\}$ ) and given in the form " $r q_{T i}-p m_{T i}-T_{i}-s t_{T i}-a c_{T i} / r f_{T i}$ ".

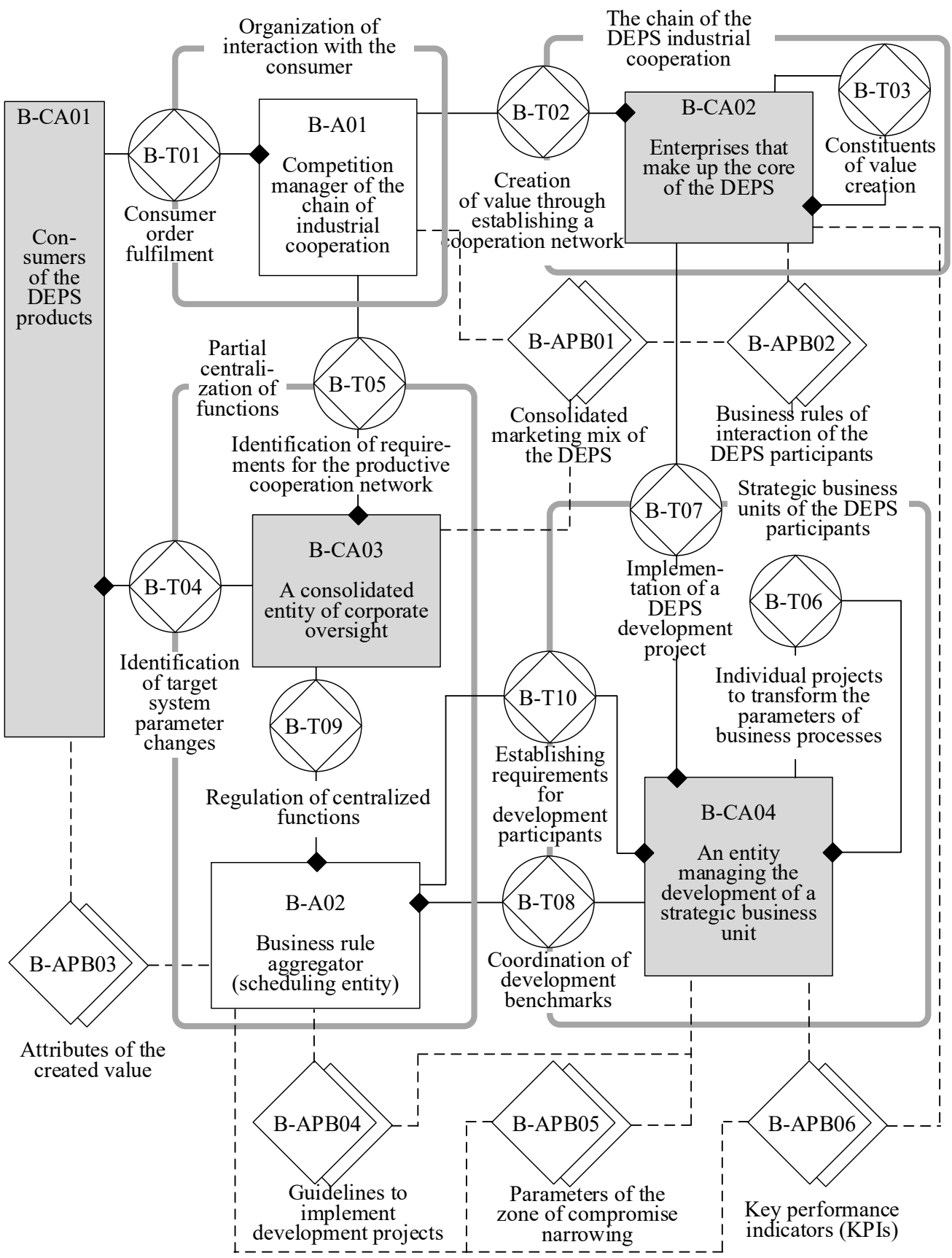

Fig. 3. A top-level model of the organization of development management of the decentralized economic production system 


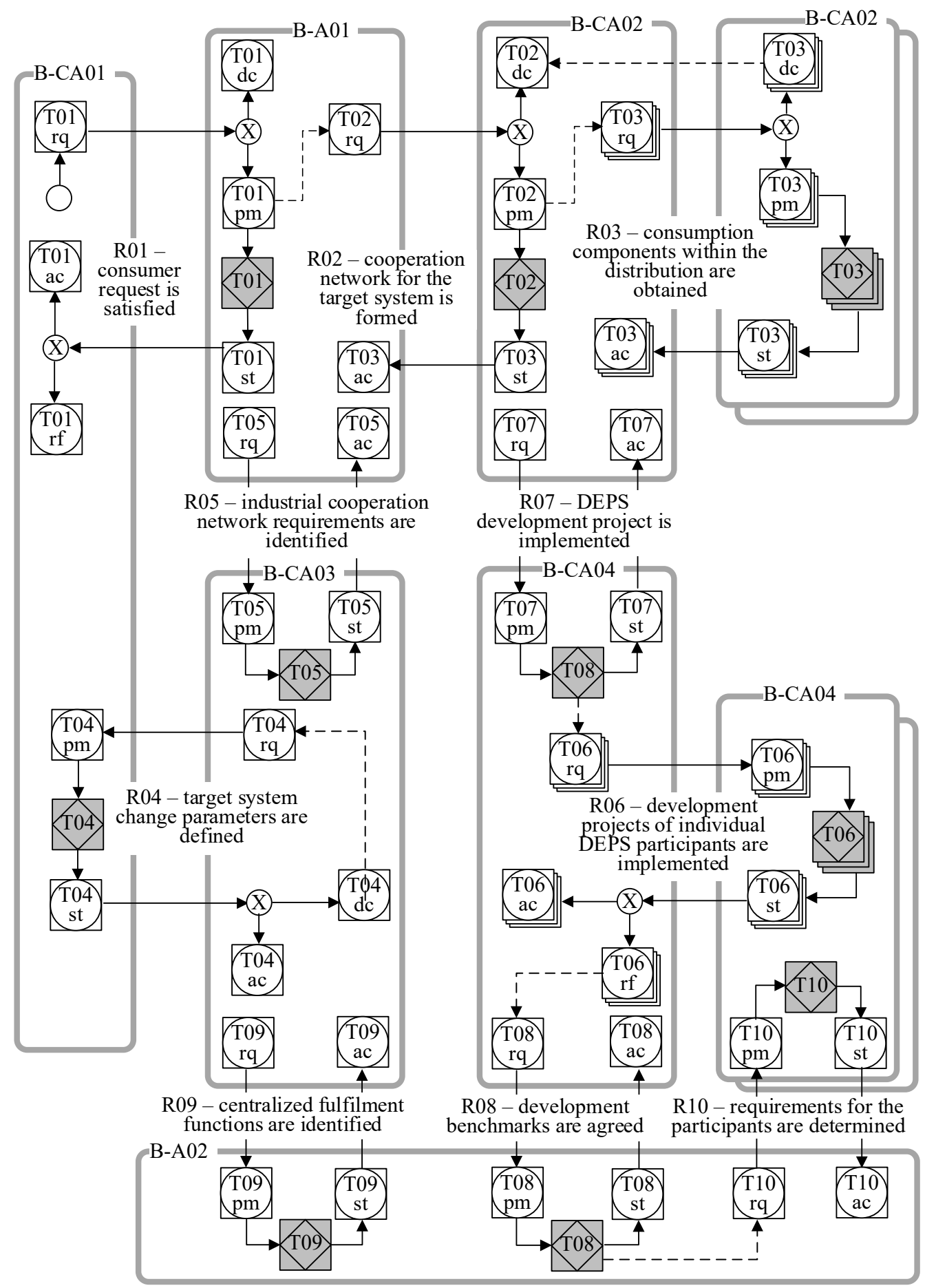

Fig. 4. Simulation of the communication process on consolidated harmonization of parameters of the DEPS participants' development projects (a PSD model in the DEMO terminology)

A positive element of the DEMO methodology is the formation of a detailed structure of the results of the interaction of the DEPS participants in the communication process. Such a structure of the results helps trace parameters of interaction of the participants of the economic production system in the part of evaluating the success of implementing the accepted obligations within the created system of business rules and guidelines of fulfilling development projects by the DEPS participants. To simplify the presentation of the study material, the proposed structure of the results is presented not in a separate diagram but in Fig. 4 in the context of displaying communication about the process the performance of which leads to the emergence of a given result from the management organization.

5. 4. Simulation of the flow of the DEPS processes (formation of the Process Structure Diagram of the DEMO methodology)

In Fig. 3, 4, the interaction models of the DEPS participants reflect the logic of the communication process but ignore the sequence of product acts. Accordingly, a flowchart in Fig. 5 is presented to simulate the process flow. This diagram is also built in terms of requests $\left(r q_{T i}\right)$ and promises $\left(p m_{T i}\right)$ of the DEPS agents to perform certain actions. 


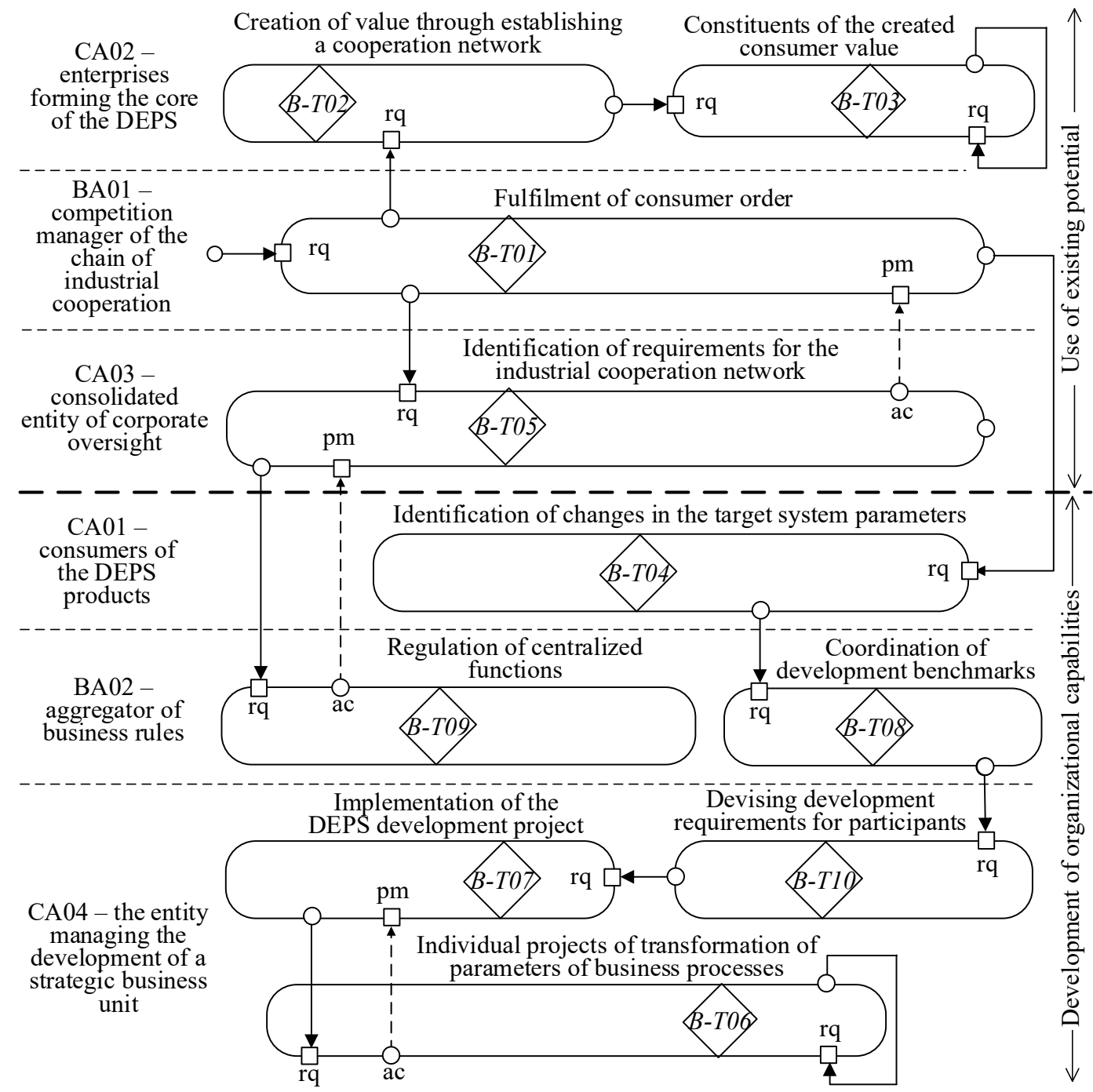

Fig. 5. Simulation of the process of functioning and development of the DEPS

It is clear that Fig. 5 presents only the top-level processes that need to be detailed using an approach to describing an entity's business processes. The advantage of the diagram is that the processes are grouped in the context of the respective actor roles (participants of the DEPS). At the beginning of the modelling process, two major types of management decisions are identified to support the functioning and development of the DEPS. Accordingly, such a grouping of processes is the basis of the DEPS process diagram in Fig. 5, which is also performed using the DEMO methodology. The identified process groups are reflected, respectively, below and above the key process that models the need to transform the business processes of the DEPS participants according to the changed parameters of the target system. This process is the key because the DEPS receives money from consolidated creation and implementation of value in the market. Accordingly, the criterion for the development of individual participants of the DEPS should be the ability to maximize the consolidated financial flow.

5. 5. Modelling the subject area of organizing interaction of the DEPS participants (formation of the State Model Diagram of the DEMO methodology)

The models shown in Fig. 3-5 are the basis for the creation of the subject area for the organization of management of the DEPS development and a ground for meaningful contents of the system of providing such management. The subject area is formed by defining the key concepts of the DEPS activities that correspond to the product transactions introduced in Fig. 3. The diagram in Fig. 3 determines the course of the communication process of the DEPS participants regarding these transactions. The diagram in Fig. 5 discloses the sequence of implementing relevant business processes in time. The diagram presented in Fig. 6 contains a list of classes of objects related to one or another transaction of the ones shown in Fig. 3. This model also defines the list of possible actions of the DEPS participants related to one or another element of the subject area. It is the presence of such a list of actions that determines the requirements for coordinating development projects of individual participants of the DEPS. The most self-identified set of such requirements will be the organization of development management of the DEPS participants stated in the purpose of the article. Moreover, a targeted development orientation is provided by the relationship between the benchmarks of the development projects and, as identified in Fig. 4, the business rules of the DEPS operation and the results of the product acts. The content of Fig. 6 shows the upper level of the ontological model of the DEPS. This diagram is the basis for the formation of managerial information systems 
of the DEPS participants. Such systems will help monitor the compliance of the DEPS participants with the development guidelines and consolidated business rules.

The development of this model is based on the use of predicate logic in its graphical interpretation given in [28]. The logic of such graphical interpretation implies using the tools of object-role modelling (fact-oriented principle description of the subject area of the research) [41], which the authors of this article have already used to form the rules of interaction of integrated entities (this development is published in [20]). In Fig. 6, the model is an extension of the research development [31] in terms of taking into account the decentralized approach to decision-making within the framework of the DEPS. This scheme, with the help of the predicates introduced, modulates the flow processes indicated in Fig. 5.
The set of models presented in the article gives an idea of the DEPS architecture. According to the TOGAF standard [42], the architecture of the DEPS should be understood as an overall business organization model, identified elements of the system, a structure and interconnection of the DEPS components, development guidelines, and the like. According to this interpretation, the organization of the management of the DEPS development will mean identification of the relevant elements of the DEPS architecture, which are modelled using the diagrams shown in Fig. 3-6. These models will determine all the major aspects of the DEPS activities (in this case, we accept the interpretation given in [43] of the architecture as a set of major decisions made in relation to a particular economic production system).

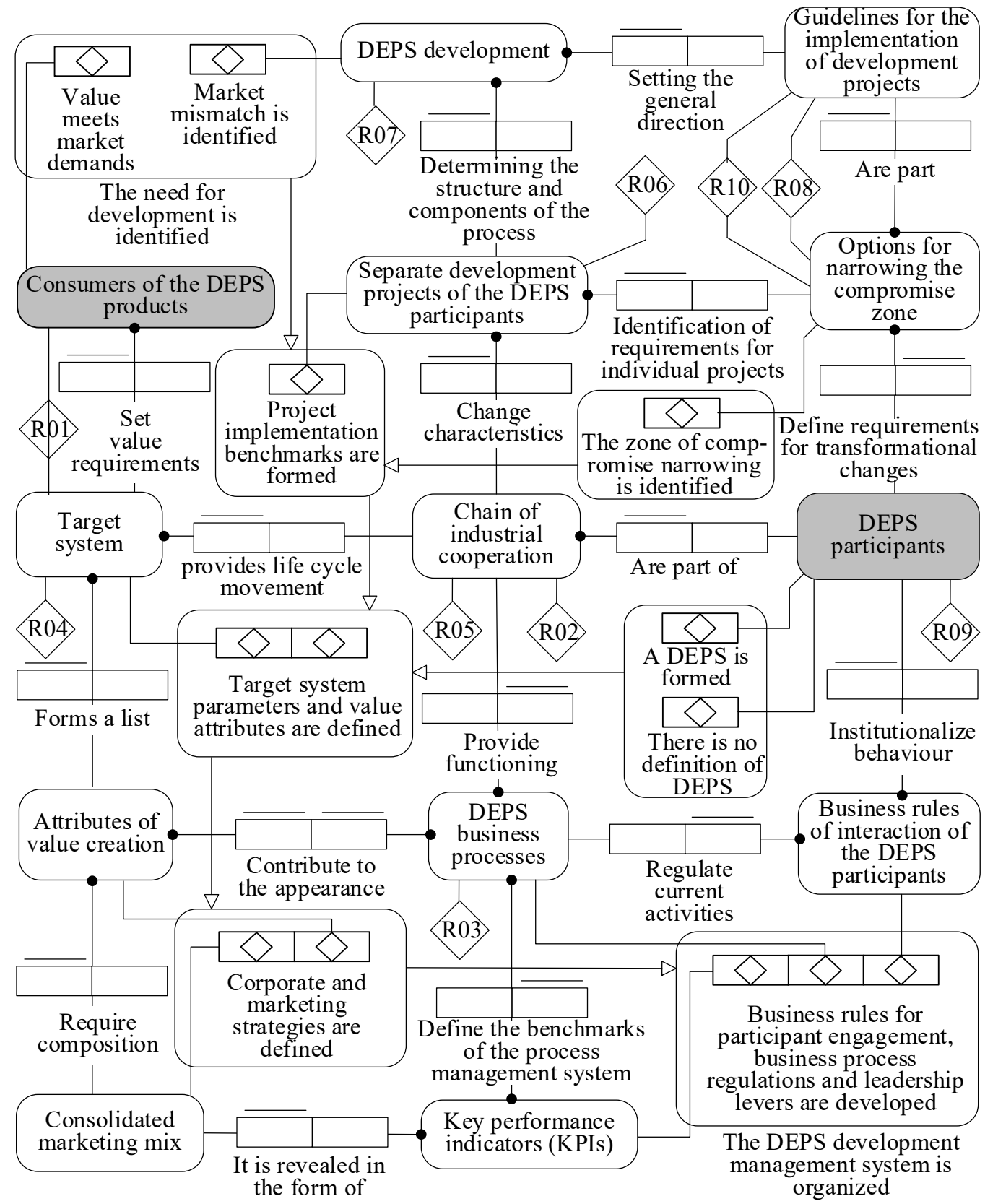

Fig. 6. A conceptual model of forming organizational support for managing the development of decentralized economic production systems 


\section{Discussion of the results of the organizational modelling and defining the rules for maintaining sustainability of the DEPS}

The proposed models of interaction of the DEPS participants are the basis of the organization of management of the economic production system development. First of all, within the frameworks indicated in Fig. 3-6, communication acts define the parameters of the DEPS development projects and harmonize such parameters by the participants of the DEPS (as presented in Fig. 1). Accordingly, the management system of each DEPS participant is oriented to work within the chosen parameters. Second, the modelling of the participants' interaction takes place within the agreed architecture of the DEPS. This architecture is the result of implementing a number of major management decisions regarding the organization of the DEPS work and the definition of the development benchmarks. Accordingly, the organization of development management of the DEPS will be reduced, firstly, to joint development of the parameters of their development projects, and secondly, to determining the set of business rules for the interaction of the participants of the economic production system regarding their participation in joint development processes. In this connection, the main advantage of the organizational models presented in the article, made using technology of business engineering, is the ability to form on their basis a certain set of management decisions to support the functioning and to determine the benchmarks for the development of the
DEPS. Accordingly, the organization of management of the DEPS development will entail improving the existing (evolutionary development) and establishing new (revolutionary development) business rules. An advantage of the DEMO methodology is the ability to relate such business rules to the product acts introduced in Fig. 3. An example of such connection regarding the organization of the management of production processes of the DEPS is given in Table 1.

There are some limitations as to applying the developed models of the interaction regulation for the DEPS participants in the practice of managing real economic objects. Such limitations imply that the business rules presented in Table 1 correspond to the maximum level of aggregation and need detailing for each level of the DEPS hierarchy. These business rules are needed first of all to determine the main directions of managing the DEPS through the use of models of communication acts. It is also noteworthy that the system of business rules in Table 1 defines the regulations and patterns of behaviour of the DEPS participants on the basis of the subject area ontology specified in Fig. 6. Orientation towards this ontology makes it possible to integrate the developed DEMO models with other modelling tools. For example, correlation of the developed models with the standard of architectural modelling ArchiMate [44] helps establish the appropriate information and infrastructure support for managing the DEPS development as well as identify the list of existing business services and software within the DEPS. The logic of such integration of models is presented in Fig. 7.

Table 1

Identification of the business rules for managing the DEPS activities (establishment of the Transaction Result Table of the DEMO methodology) [31]

\begin{tabular}{|c|c|c|}
\hline $\begin{array}{l}\text { Number of the global model } \\
\text { transaction }\end{array}$ & Result of the transaction & $\begin{array}{l}\text { Components of the organized management of the DEPS devel- } \\
\text { opment and the activities of its participants }\end{array}$ \\
\hline $\begin{array}{l}\text { T01 - fulfilment of the consumer } \\
\text { order }\end{array}$ & $\begin{array}{l}R 01-\text { the consumer request for market } \\
\text { value is satisfied }\end{array}$ & $\begin{array}{l}\text { Business rules on the terms, quality, completeness and timing o } \\
\text { consumer orders }\end{array}$ \\
\hline $\begin{array}{l}\text { T02 - creation of consumer val- } \\
\text { ue through the establishment of } \\
\text { a cooperation network }\end{array}$ & $\begin{array}{l}R 02-\text { cooperation network to implement } \\
\text { the target system is formed }\end{array}$ & $\begin{array}{l}\text { Descriptions of the DEPS business architecture elements are } \\
\text { added to the corporate portal. A description of the attributes } \\
\text { of value creation and the accepted requirements for their char- } \\
\text { acteristics }\end{array}$ \\
\hline $\begin{array}{l}\text { T03 - components of value cre- } \\
\text { ation }\end{array}$ & $\begin{array}{l}R 03 \text { - separate components of consumer } \\
\text { value within the framework of distribut- } \\
\text { ing business processes among the DEPS } \\
\text { participants are received }\end{array}$ & $\begin{array}{l}\text { A detailed description of the requirements for attributes of val- } \\
\text { ue creation in the context of detailing through business process- } \\
\text { es. Local business rules are adopted by all DEPS participants } \\
\text { and key stakeholders }\end{array}$ \\
\hline $\begin{array}{l}T 04-\text { identi } \\
\text { of the target }\end{array}$ & $\begin{array}{l}\text { ars of change of the target } \\
\text { led }\end{array}$ & $\begin{array}{l}\text { Design documentation } \\
\text { A list of lifecycle prac } \\
\text { system }\end{array}$ \\
\hline $\begin{array}{l}\text { T05 - identification of require- } \\
\text { ments for the industrial cooper- } \\
\text { ation network }\end{array}$ & $\begin{array}{l}R 05-\text { requirements for the industrial } \\
\text { cooperation network within the DEPS } \\
\text { are identified }\end{array}$ & $\begin{array}{llllll} & 1\end{array}$ \\
\hline $\begin{array}{l}\text { T06 - individual projects of } \\
\text { transformations of business pro- } \\
\text { cesses of the DEPS participants }\end{array}$ & $\begin{array}{l}R 06 \text { - projects for the development of } \\
\text { individual participants of the DEPS are } \\
\text { implemented }\end{array}$ & $\begin{array}{l}\text { Paral } \\
\text { ing } p \\
\text { and } 1\end{array}$ \\
\hline $\begin{array}{l}\text { T07 - implementation of a proj- } \\
\text { ect of the DEPS development }\end{array}$ & $\begin{array}{l}\text { oject of the DEPS develop- } \\
\text { emented }\end{array}$ & $\begin{array}{l}\text { Supplier } \\
\text { compron }\end{array}$ \\
\hline $\begin{array}{l}\text { T08 - harmonization of develop- } \\
\text { ment guidelines }\end{array}$ & $\begin{array}{l}R 08-\text { development guidelines and param- } \\
\text { eters for narrowing the compromise zone } \\
\text { are agreed }\end{array}$ & $\begin{array}{l}\text { Regulations of corporate oversight. Indica } \\
\text { the DEPS activities in terms of key charac } \\
\text { ticipants' business processes }\end{array}$ \\
\hline $\begin{array}{l}\text { T09 - regulation of centralized } \\
\text { functions }\end{array}$ & $\begin{array}{l}R 09-\text { functions with centralized perfor- } \\
\text { mance are regulated }\end{array}$ & $\begin{array}{l}\text { A list of marketing and financial indicators. Results of modellir } \\
\text { interaction parameters. Micro-institutes and control concep } \\
\text { are created }\end{array}$ \\
\hline $\begin{array}{l}T 10 \text { - setting development re- } \\
\text { quirements for the DEPS par- } \\
\text { ticipants }\end{array}$ & $\begin{array}{l}R 10 \text { - requirements for development } \\
\text { projects of the DEPS participants are } \\
\text { established }\end{array}$ & $\begin{array}{l}\text { Mutual coordination of requirements for the parameters } \\
\text { interrelated development projects, achieved as a result of inte } \\
\text { active communications }\end{array}$ \\
\hline
\end{tabular}




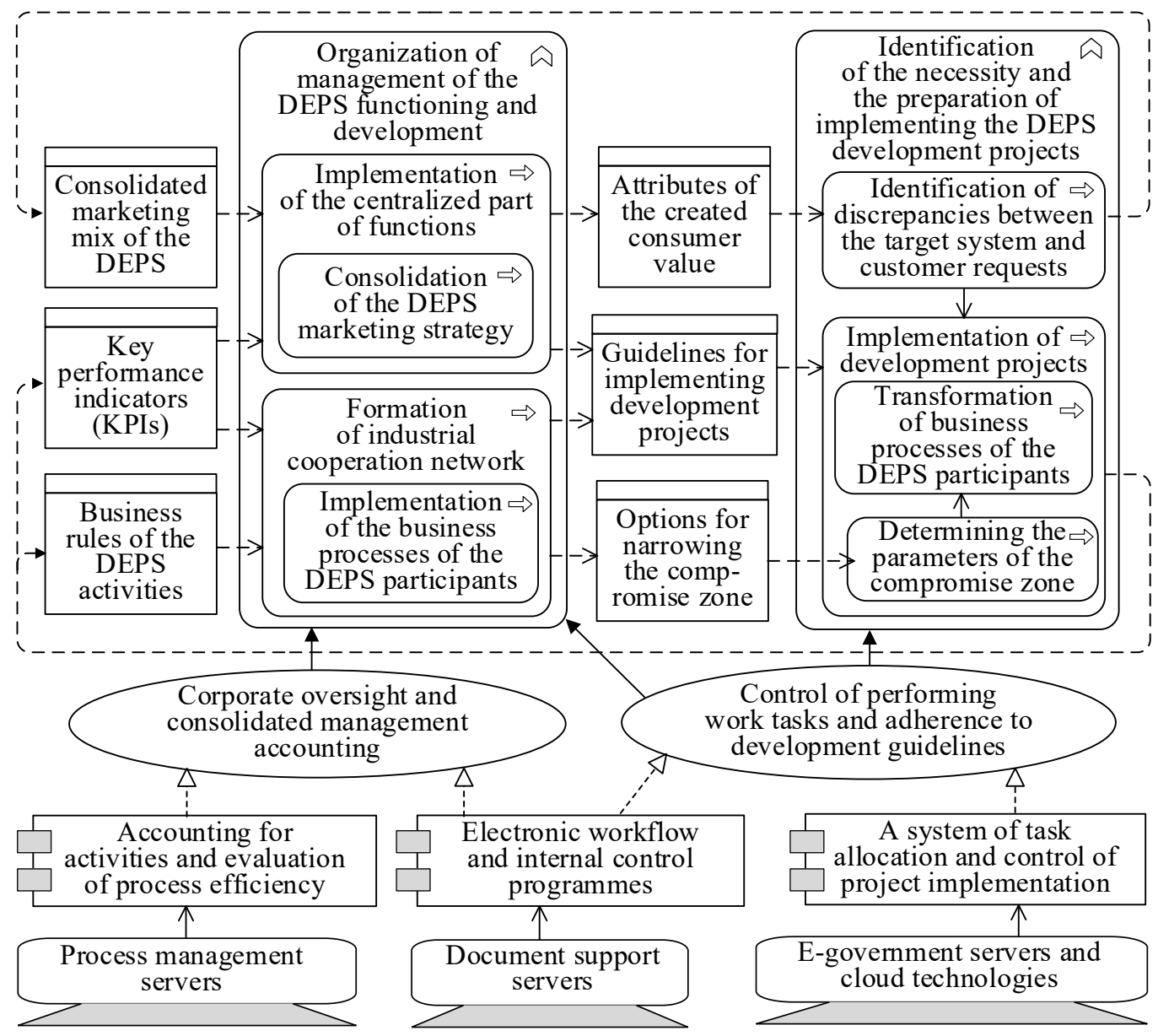

Fig. 7. Harmonization of organizational support for the processes of managing the functioning and development of the DEPS based on a service-oriented paradigm

The diagram in Fig. 7 uses the approach proposed in [36] to present DEMO product acts as elements of ArchiMate notation business processes [44]. This approach was already used by the authors in [31] to regulate the formation of an industrial cooperation network and to standardise logistics functions. The model in Fig. 7 focuses on the recursive reflection of changes in the development processes and management organization of the DEPS development. For this purpose, the diagram of Fig. 7 is supplemented with the elements of the domain model that were declared in Fig. 6. The advantage of ArchiMate notation is the combination of a single model of three levels that describes the business logic of the production system (this logic is presented in the article using the DEMO approach) in close connection with the work of information systems. Therefore, the model in Fig. 7 is supplied with the reflected levels of providing information services and physical infrastructure.

Nevertheless, the results obtained require further research in order to bring the developments closer to practical implementation. First of all, it is necessary to expand the developed ontology of the subject area in terms of supplementing it with the components of interaction of specific participants of the DEPS. This extension of the ontology may in the future serve as a basis for the formation of a work plan of accounts of management accounting for the DEPS participants. Besides, the diagram of Fig. 7 shows only the logic of integrating the DEMO methodology and the ArchiMate architectural modelling language. Accordingly, it is necessary to develop more detailed models using ArchiMate, which would determine the implementation features declared by DEMO communication and product acts. Such models, in their turn, will form the basis for a detailed description of the logic of business processes of interaction of the DEPS participants. This type of description can be obtained using, for example, the Business Process Model Notation (BPMN) approach. In this case, the models presented in the article and their ArchiMate extensions will act as aggregate process models.

\section{Conclusion}

1. The study has proved the necessity to take into account the possibility of decentralized decision-making by locally optimized economic entities while organizing the management of integrated economic production systems. Such decentralization has identified the peculiarities of establishing organizational support for the management of the decentralized economic production systems. The creation of such security is represented by the formation of a set of business rules distributed among the participants of the economic production system and the regulation of projects of transformational revision of such business rules by the DEPS participants.

2. The technology of Design and Engineering Methodology for Organizations, DEMO, is used as a theoretical and methodological basis to organize management of the 
development of decentralized economic production systems. Within the framework of applying the DEMO methodology, we have identified a set of key roles of stakeholders whose interaction defines the guidelines for the development of the economic production system. The application of the DEMO methodology has helped develop a set of top-level communication models of participants of economic production systems and substantiate a system of rules for narrowing the zone of compromises regarding the parameters of organizational development of the economic production system. It has been proved that the organization of managing the DEPS sustainability should be based on control of communication parameters of its participants.

3. The developed models are proposed to be used in the consolidation of strategic decisions by the responsible persons of the decentralized economic production system. In order to achieve such consolidation, a component of partial centralization of management processes and subordinate models of strategic business units in the structure of the DEPS participants have been identified. The main objective of these models is to facilitate the communication process of the key stakeholders. In addition, it is proposed to correlate the DEMO models with standards for architectural modelling of the systems. The logic of such correlation is presented by the example of ArchiMate architectural modelling language. The appropriateness of such correlation is conditioned by the creation of a basis for the deployment of a corporate management information system and the development of business processes of the economic production system.

\section{References}

1. Nielsen, C. B., Larsen, P. G., Fitzgerald, J., Woodcock, J., Peleska, J. (2015). Systems of Systems Engineering. ACM Computing Surveys, 48 (2), 1-41. doi: https://doi.org/10.1145/2794381

2. Varga, P., Blomstedt, F., Ferreira, L. L., Eliasson, J., Johansson, M., Delsing, J., Martínez de Soria, I. (2017). Making system of systems interoperable - The core components of the arrowhead framework. Journal of Network and Computer Applications, 81, 85-95. doi: https://doi.org/10.1016/j.jnca.2016.08.028

3. Huang, J., Shuai, Y., Liu, Q., Zhou, H., He, Z. (2018). Synergy Degree Evaluation Based on Synergetics for Sustainable Logistics Enterprises. Sustainability, 10 (7), 2187. doi: https://doi.org/10.3390/su10072187

4. Shao, Y., Han, S. (2019). The Synergy in the Economic Production System: An Empirical Study with Chinese Industry. Sustainability, 11 (4), 980. doi: https://doi.org/10.3390/su11040980

5. Verdecho, M.-J., Alfaro-Saiz, J.-J., Rodríguez-Rodríguez, R. (2019). Integrating Business Process Interoperability into an Inter-enterprise Performance Management System. Enterprise Interoperability VIII, 265-273. doi: https://doi.org/10.1007/978-3-03013693-2_22

6. Gutsalyuk, O. M. (2017). an innovative component in managing the efficiency of corporate enterprise integration transformation. Visnyk Odeskoho natsionalnoho universytetu. Seriya: Ekonomika, 22 (10), 102-108.

7. Akhmetshin, E. M., Kolpak, E. P., Sulimova, E. A., Kireev, V. S., Samarina, E. A., Solodilova, N. Z. (2017). Clustering as a Criterion for the Success of Modern Industrial Enterprises. International Journal of Applied Business and Economic Research, 15 (23), $221-231$.

8. Kotusev, S. (2018). TOGAF-based Enterprise Architecture Practice: An Exploratory Case Study. Communications of the Association for Information Systems, 321-359. doi: https://doi.org/10.17705/1cais.04320

9. Lopez, C.-P., Segura, M., Santórum, M. (2019). Framework to Develop a Business Synergy through Enterprise Architecture. Proceedings of the 2019 2nd International Conference on Information Science and Systems - ICISS 2019. doi: https://doi.org/ $10.1145 / 3322645.3322668$

10. Machado, N., Parambi, K., Venkatesan, P. (2017). Structure Follows Strategy at Bharat Petroleum. South Asian Journal of Business and Management Cases, 6 (2), 150-166. doi: https://doi.org/10.1177/2277977917727436

11. Killingsworth, P., Eschenbacher, L. (2018). Designing organizational structures: Key thoughts for development. American Journal of Health-System Pharmacy, 75 (7), 482-492. doi: https://doi.org/10.2146/ajhp170657

12. Seifzadeh, P. (2016). Strategy and competitiveness: an integrated perspective on economic based theories in strategic management. European Journal of Management, 16 (1), 53-62. doi: https://doi.org/10.18374/ejm-16-1.5

13. Kownatzki, M., Walter, J., Floyd, S. W., Lechner, C. (2013). Corporate Control and the Speed of Strategic Business Unit Decision Making. Academy of Management Journal, 56 (5), 1295-1324. doi: https://doi.org/10.5465/amj.2011.0804

14. Bgane, Y. K. (2015). Crises in the evolution of economic systems of inhomogeneous. Nauchniy zhurnal KubGAU, 107 (03).

15. Sun, B., Wang, H. (2016). The Impact of Enterprise Heterogeneity on the Diffusion of Technological Innovation. International Journal of u- and e- Service, Science and Technology, 9 (9), 17-26. doi: https://doi.org/10.14257/ijunesst.2016.9.9.03

16. Sadigh, B. L., Nikghadam, S., Ozbayoglu, A. M., Unver, H. O., Dogdu, E., Kilic, S. E. (2017). An ontology-based multi-agent virtual enterprise system (OMAVE): part 2: partner selection. International Journal of Computer Integrated Manufacturing, 30 (10), 1072-1092. doi: https://doi.org/10.1080/0951192x.2017.1285424

17. Katkova, M. A., Mityaeva, N. V. (2014). Irregularity of the institutional system development: the phenomenon of fundamental nature of casual. Vestnik REU, 11, 16-25.

18. Vygolko, T. A. (2014). The analysis of the economic power in the works by J. K. Galbraith. Vestnik instituta ehkonomicheskih issledovaniy, 4, 81-89.

19. Dementiev, V. E., Evsukov, S. G., Ustyuzhanin, V. L., Ustyuzhanina, E. V. (2018). Economic Power and Distribution of Added Value (illustrated by aircraft building). Vestnik of the Plekhanov Russian University of Economics, 6, 3-15. doi: https://doi.org/ 10.21686/2413-2829-2018-6-3-15 
20. Pylypenko, A., Lytvynenko, A. (2017). Institutional and architectural design of organisational development of large-scale economic and industrial systems. Economic Annals-XXI, 165 (5-6), 75-79. doi: https://doi.org/10.21003/ea.v165-16

21. Pylypenko, A., Popov, A. (2017). Development of information consolidation system in the reflective management of large-scale economic and production systems. Eastern-European Journal of Enterprise Technologies, 4 (3 (88)), 56-65. doi: https://doi.org/ 10.15587/1729-4061.2017.108929

22. Shmatko, N. (2018). The large-scale economic and industrial systems structural and organizational sustainability ensuring through enterprise engineering methodology. Nauka i Studia, 14 (194), 3-13.

23. Yakovleva, E., Grigoryeva, N., Grigoryeva, O. (2016). Opportunistic Behavior as Behavior Manipulations. American Journal of Applied Sciences, 13 (9), 996-1005. doi: https://doi.org/10.3844/ajassp.2016.996.1005

24. Moloney, M., Fitzgibbon, K., McKeogh, E. (2017). Systems-of-systems methodology for strategic infrastructure decision making: Ireland as a case study. Civil Engineering and Environmental Systems, 34 (3-4), 185-205. doi: https://doi.org/10.1080/ 10286608.2018.1447568

25. Shirazi, B. (2018). Towards a sustainable interoperability in food industry small \& medium networked enterprises: Distributed service-oriented enterprise resources planning. Journal of Cleaner Production, 181, 109-122. doi: https://doi.org/10.1016/j.jclepro.2018.01.118

26. Bourne, M., Franco-Santos, M., Micheli, P., Pavlov, A. (2017). Performance measurement and management: a system of systems perspective. International Journal of Production Research, 56 (8), 2788-2799. doi: https://doi.org/10.1080/00207543.2017.1404159

27. Op’t Land, M., Dietz, J. L. G. (2012). Benefits of Enterprise Ontology in Governing Complex Enterprise Transformations. Advances in Enterprise Engineering VI, 77-92. doi: https://doi.org/10.1007/978-3-642-29903-2_6

28. Dietz, J. (2006). Enterprise Ontology. Theory and Methodology. Springer, 240. doi: https://doi.org/10.1007/3-540-33149-2

29. Janssen, T. (2016). Enterprise Engineering. Sustained Improvement of Organizations. Springer, 148. doi: https://doi.org/ 10.1007/978-3-319-24172-2

30. Hoogervorst, J. (2009). Enterprise Governance and Enterprise Engineering. Springer. doi: https://doi.org/10.1007/978-3-54092671-9

31. Shmatko, N. M. (2019). Orhanizatsiynyi rozvytok velykomasshtabnykh ekonomiko-vyrobnychykh system: pidtrymka stiykosti ta instytutsionalizatsiya vzaiemodiyi. Kharkiv: Tekhnolohichnyi tsentr, 368.

32. ISO/IEC/IEEE 24748-2. Systems and software engineering - Life cycle management - Part 2: Guidelines for the application of ISO/ IEC/IEEE 15288 (System life cycle processes) (2018). Switzerland: Institute of Electrical and Electronics Engineers, Inc., 64.

33. Aldea, A., Iacob, M. E., Lankhorst, M. (2016). Capability-Based Planning: The Link between Strategy and Enterprise Architecture. United Kingdom: The Open Group, 35.

34. Archimède, B., Vallespir, B. (Eds.) (2017). Enterprise Interoperability. John Wiley \& Sons, 237. doi: https://doi.org/10.1002/ 9781119407928

35. Mertins, K., Bénaben, F., Poler, R., Bourrières, J.-P. (Eds.) (2014). Enterprise Interoperability VI. Interoperability for Agility, Resilience and Plasticity of Collaborations. Springer. doi: https://doi.org/10.1007/978-3-319-04948-9

36. Kuz'minov, Ya. I., Bendukidze, K. A., Yudkevich, M. M. (2006). Kurs institutsio-nal'noy ehkonomiki: instituty, seti, transaktsionnye izderzhki, kontrakty. Moscow: Izd. dom. GU VShE, 442.

37. Op’t Land, M., Proper, E., Waage, M., Cloo, J., Steghuis, C. (2009). Enterprise Architecture. Creating Value by Informed Governance. Springer. doi: https://doi.org/10.1007/978-3-540-85232-2

38. Hunka, F, van Kervel, S. J. H., Matula, J. (2018). The DEMO Co-creation and Co-production Model and Its Utilization. Enterprise and Organizational Modeling and Simulation, 138-152. doi: https://doi.org/10.1007/978-3-030-00787-4_10

39. Kudryavtsev, D. V., Arzumanyan, M. Yu., Grigor'ev, L. Yu. (2014). Tehnologii biznes-inzhiniringa. Sankt-Peterburg: Izdatel'stvo politehnicheskogo universiteta, 427.

40. Modelworld. Available at: http://www.modelworld.nl/

41. Halpin, T. (2015). Object-Role Modeling Fundamentals. A Practical Guide to Data Modeling with ORM. New Jersey: INTI International University, 192.

42. The TOGAF Standard. Version 9.2 (2018). U.S.: The Open Group, 532.

43. Levenchuk, A. I. (2018). Sistemnoe myshlenie. Moscow: Izdatel'skie resheniya, 440.

44. ArchiMate ${ }^{\circledR}$ 3.0.1 Specification. Available at: http://pubs.opengroup.org/architecture/archimate3-doc/toc.html 